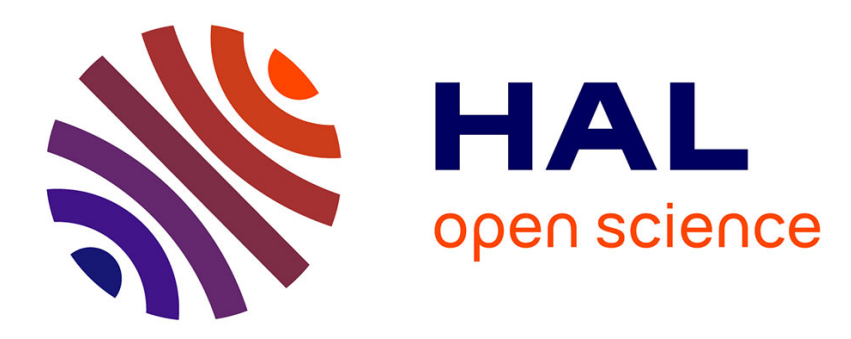

\title{
DYNAMIC FRACTURE OF UNIDIRECTIONAL COMPOSITES AT HIGH-RATE STRAIN
}

\author{
V. Kornev, A. Demeshkin
}

\section{To cite this version:}

V. Kornev, A. Demeshkin. DYNAMIC FRACTURE OF UNIDIRECTIONAL COMPOSITES AT HIGH-RATE STRAIN. Journal de Physique IV Proceedings, 1991, 01 (C3), pp.C3-681-C3-686. 10.1051/jp4:1991395 . jpa-00250541

\section{HAL Id: jpa-00250541 https://hal.science/jpa-00250541}

Submitted on 1 Jan 1991

HAL is a multi-disciplinary open access archive for the deposit and dissemination of scientific research documents, whether they are published or not. The documents may come from teaching and research institutions in France or abroad, or from public or private research centers.
L'archive ouverte pluridisciplinaire HAL, est destinée au dépôt et à la diffusion de documents scientifiques de niveau recherche, publiés ou non, émanant des établissements d'enseignement et de recherche français ou étrangers, des laboratoires publics ou privés. 
Colloque C3, suppl. au Journal de Physique III, Vol. 1, octobre 1991

\title{
DYNAMIC FRACTURE OF UNIDIRECTIONAL COMPOSITES AT HIGH-RATE STRAIN
}

\author{
V.M. KORNEV and A.G. DEMESHKIN
}

Lavrentyev Institute of Hydrodynamics, Novosibirsk 630090, USSR

\begin{abstract}
résumé: Les expériences réalisées ont montré : 1/ l'accroissement essentiel de la déformation limite d'anneaux de verre, plastiques et organoplastiques avec la vitesse de déformation. 2/ l'égalité des modules élastiques statique et dynamique. Une théorie est proposée décrivant la durée de vie de l'échantillon, tenant compte du fluage et de la porosité induite.
\end{abstract}

Abstract. The experiments performed have shown 1) the essential increase in the limiting deformation of glass plastic rings and organoplastic ones with strain rates, and 2) the coincidence of the dynamic elasticity modulus with the static one. A theory has been proposed that describes the specimen lifetime with allowance for creep and induced porosity.

\section{I . INTRODUCT ION}

Recently the fibrous composite materials are widely used to produce the parts and assemblies of structures working under dynamic loading. In this connection it is important to study and predict the elastic strength properties of composites depending on the peculiar characteristic strain rate. The data available in literature on this problem are, in a certain respect, contradictory and hardly comparable since the researchers choose for investigations the different types of composites and confine themselves by a rather narrow range of peculiar strain rates.

\section{I EXPERIMENTAL RESULTS}

For the experiments, use was made of the shock method of loading unidirectional composite rings. The internal surface of the ring was loaded by liquid pressure. The pressure in a closed liquid volume was created by a striker accelerated preliminarily up to the required velocity. To obtain high strain rates of ring deformation, the unit was designed and produced that gave the pressure exceeding 1 kbar in a compression chamber. The main element of the unit is the hydropneumatic hammer. We were a success to change essentially the rate of liquid pressure increase in the compression chamber at the expense of a replaceable striker of the hammer. The specifications of the unit are such that for different specimens we were a success to attain the characteristic values of strain rates from $10 \mathrm{~s}^{-1}$ to $400 \mathrm{~s}^{-1}$ at good experimental replication. A ring specimen produced by coiling was placed into a centering unit 
housing. The housing with the specimen was placed 这o a cylindrical chamber where the liquid (water or glycerine) pressure was created. The rate of pressure increase and the maximum liquid pressure in a chamber are due to the velocity of the striker at the moment of the striker impact on the liquid surface and to the liquid compressibility. In some cases the chambers different from the cylindrical ones were used. The modified chambers allow the control of the rate of pressure increase and maximum liquid pressure in the compression chamber to be carried out.

The liquid pressure in the compression chamber was measured by a pressure piezogauge that was calibrated statically and dynamically by steel rings of various thickness. The material of these elastic rings was chosen such that not to respond to the strain rate changes.

To measure the circumferential deformation, use was made of a ring strain gauge as in the static experiments. The pulse signals from the ring strain gauge and the pressure gauge were registered by a digital (or ray) memory oscillographs.

In the experiments the profiles of curves of the circumferential deformation $\varepsilon=\varepsilon(t)$ and of pressure $p=p(t)$ as the function of time $t$ were obtained. The oscillograms were processed as follows. For the fixed time moment $t_{1}$ (for example, the time of an abrupt pressure drop $p$ ), the pressure $p\left(t_{1}\right)$ registered by the pressure gauge was determined. The pressure value obtained was taken to correspond to the deformation $\varepsilon\left(t_{1}+\Delta t\right)$ with the allowance for pressure signal delay since the pressure gauge was placed below the specimen tested at a distance of $20 \mathrm{~mm}$ from its middle part. The ring specimen stress $\sigma(t)$ was calculated according to formula/1/

$$
\sigma(t)=p(t) R / h+\varepsilon "(t) R^{2} \rho_{k} / \alpha^{2},
$$

where $R$ is the internal ring radius, $h$ is the ring wall thickness, $\rho_{k}$ is the ring material density, $\alpha$ is the coefficient that takes into account inertia of the ring material and transmitting medium. In some experiments, the ring acceleration $\varepsilon$ ( $t$ ) was registered directly. To estimate the influence of the inertia term on the curve character, the calculations were made, which showed that the inertia term can be neglected when the strain rate ranges from 200 to $250 \mathrm{~s}^{-1}$, since its contribution doesn't exceed $3 \%$ as compared to the first term (see (2.1)). At strain rates exceeding $250 \mathrm{~s}^{-1}$, it is expedient to take into account the inertia term influence.

Fracture of composite specimens is characterized by delamination into separate narrow rings. The specimens of organoplastic give a larger number of rings than those of glass plastic. Between the narrow organoplastic rings formed, the fibers become hairy, i.e. the looseness of organoplastic specimen material is observed at fracture. The volume of the specimen increases by some times. The glass plastic almost doesn't change its volume at fracture. With the strain rate, a tendency is observed to an increase in a number of teared fibers of the glass plastic specimen and to formation of separate segments. Replication of the experiments is quite good.

The experiments performed show: 1) the essential increase in the limiting deformation under intense loading, for example, from $2.1 \%$ 
to $4.0 \%$ for glass plastic under strain rates ranging from $10 \mathrm{~s}^{-1}$ to $300 \mathrm{~s}^{-1}$ and from $1.3 \%$ to $2.1 \%$ for organoplastic under strain rates ranging from $10 \mathrm{~s}^{-1}$ to $300 \mathrm{~s}^{-1}$ (see Fig.1); 2) the elastic deformation of materials tested practically as long as fracture occurs. Thus, with the strain rates, both the limiting deformations and fracture stresses increase. The elasticity modulus change is not observed with an accuracy up to a spread band of the experimental data. The experimental results obtained aren't always in agreement with those ones presented in papers $/ 2-5 /$.

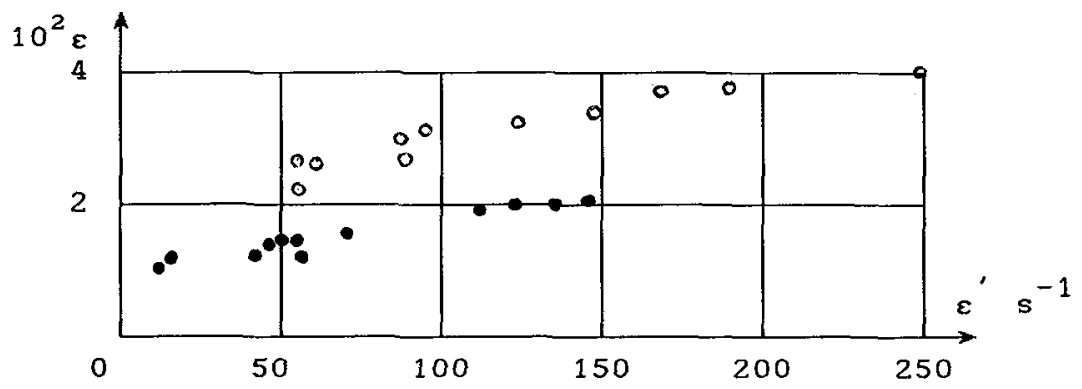

Fig. 1. Limiting deformation versus strain rate.

- glass plastic, - organoplastic

\section{THE SPECIMEN LIFETIME AT TENSION}

Let us consider the fracture of a homogeneous specimen extended by a variable force $P(t)$. Now we'll try to combine traditional approaches in physics and mechanics to determination of the material lifetime, i.e. we'll analyze the fracture of a homogeneous specimen using the thermofluctuation fracture theory and classical results on material deformation under creep. Thus, consider a system of two equations, the first of which is the Zhurkov's equation and the second one is the classical creep equation using the power law,

$$
\begin{aligned}
d N / d t= & \left(N_{0} v / A\right) \exp \left[-\left(u_{0}-\gamma \sigma_{e}\right) / k T\right], \\
& l^{-1} d 1 / d t=B \sigma^{m} .
\end{aligned}
$$

Here $N(t)$ is the change of a number of bonds (break of bonds in an ordered structure), $N_{0}$ being the initial number of interatomic bonds, $l(t)$ is the specimen length, $t$ is the time, $l(0)=l_{0}$ is the initial specimen length, $v$ is the frequency of thermal fluctuations of atoms, $u_{0}$ is the energy of unloaded bond, $A$ and $B$ are the proportionality coefficients, $\gamma$ denotes the material constant, $k$ is the Boltzmann constant, $T$ is the absolute temperature, $\sigma_{e}$ is the efficient and real stress in the overstressed bonds, $\sigma$ is the stress averaged in the cross-section, $m$ is the index in the power creep law.

Two equations of system (3.1) describe different processes, i.e. the first equation is for local effects of rapture of interatomic 
bonds and the second one describes the averaged specimen behaviour. Physicians often consider that the first equation "works" for short-time fracture regimes, and researchers in mechanics consider only the second equation that "works" for long-time fracture regimes under creep.

The mass conservation law connects the initial and current values of the density $\rho$, length $l$ and cross-section area $F$ of the specimen; the averaged stresses o are found as usually:

$$
\rho_{0} l_{0} F_{0}=\rho 1 F, \quad \sigma=P / F=\sigma_{0} F_{0} / F, \quad \sigma_{0}(t)=P(t) / F_{0},
$$

One of possible approximations of the efficient stress $\sigma_{e}$ takes the following form with the help of the averaged stresses $\sigma_{0}$ (see $/ 6 /$, page 144$)$, i.e.

$$
\sigma_{e}=\sigma_{0}\left(\rho_{0} / \rho\right)^{n} F_{0} / F
$$

where $n$ is the index of crack formation, its value takes into account the effect of dilatation on fracture characteristics (see section 2).

The allowance for relations (3.2) - (3.3) transforms the initial system of equations ( 3.1 ) to

$$
\begin{gathered}
d N / d t=\left(N_{0} v / A\right) \exp \left\{-\left[u_{0}-\gamma \sigma_{0}\left(\rho_{0} / \rho\right)^{n} F_{0} / F\right] / k T\right\}, \\
l^{-1} d l / d t=B \sigma_{0}^{m}\left(1 / l_{0}\right)^{m}\left(\rho / \rho_{0}\right)^{m} .
\end{gathered}
$$

This system is solved with following initial conditions

$$
N(0)=0, \quad l(0)=l_{0} \quad\left(N(t) \leqslant N_{0}\right) .
$$

The breakdown of a part of interatomic bonds $\beta N_{0}(O<\beta \leqslant 1)$ results in fracture, i.e. the critical fracture time $t_{*}$ is found from relation

$$
N\left(t_{*}\right)=\beta N_{0} .
$$

It is obvious that among the solutions of problem (3.4), (3.5) there must exist the solutions corresponding to the thermofluctuation fracture process and those ones of fracture under creepn (viscous or brittle fracture processes). In addition, some combined regimes of deformation and fracture are possible. An analysis performed shows that schematically different processes can be represented by the curves on the $t_{*}-\sigma_{0}$ diagram for the constant tension $\sigma_{0}=$ const (see Fig. 2). In the general case, the existence of three different fracture regimes can be expected. This is illustrated by a thick curve. The $t_{*}-\sigma_{0}$ diagram presented is different from the analogous diagrams taken from books $/ 7$, $8 /$ by that it has the regions corresponding to the fracture under creep (see /6, 9/). Surely, some regimes for certain materials can be absent. A considerable body of experimental data is given in 
$/ 10 /($ see pp. 31, 33, 37, 103-110).

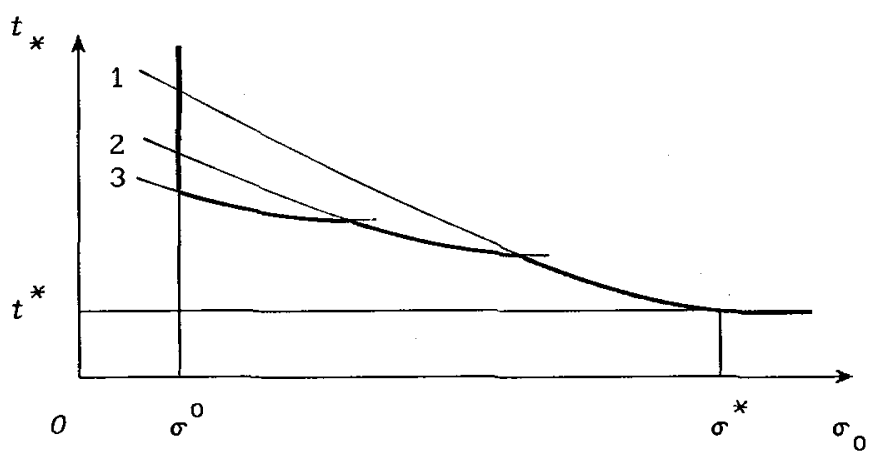

Fig.2. Diagram of possible fracture regimes. Curve 1 - thermofluctuation fracture prcess, curve 2 - viscous fracture under creep, curve 3 - brittle fracture under creep, $t^{*}$ and $\sigma^{*}$ are the critical time and stress, corresponding to athermic fracture, $\sigma^{\circ}-$ is the safety stress.

Let us assume that the second equation solution of system (3.5) has been already built for viscous (or brittle) deformation regimes with allowance for material dilatation (see /9/). Transformation of the first equation of system (3.5) gives the equation with variable coefficients in the form

$$
d N=\left(N_{0} v / A\right) \exp \left[-u_{0} / k T\right] \cdot \exp (t) d t .
$$

The equation given for describing the thermofluctuation fracture process under the time-variable tension $\sigma_{0}=\sigma_{0}(t)$ has the same form.

Solutions of equation (3.7) in a closed form are easily obtained for two cases: 1) when the function $x(t)$ in the vicinity of the point $t_{*}$ is represented with a sufficient accuracy by the first two terms of the Taylor series (further, the calculations are clear), 2) when the integral of equation (3.7) is estimated by the Laplace asymptotic methods (see theorem 1.2.3, p.18 in /11/). From these integrals, with the allowance for (3.6) we'll derive the following expressions to determine the critical fracture time, i.e. for the first case

$$
\beta N_{0} \cong \frac{N_{0} \nu}{A} \exp \left(-\frac{u_{0}}{k T}\right) \cdot\left[t_{*}-\frac{t_{*}^{2}{ }^{\prime}\left(t_{*}\right)}{2}\right) \exp \left(t_{*}\right),
$$

for the second case

$$
\beta N_{0} \cong-\frac{N_{0} v}{A} \exp \left[-\frac{u_{0}}{k T}\right] \cdot \frac{\exp \left(t_{*}\right)}{x\left(t_{*}\right)} .
$$


It should be noted that the relations presented are not reduced one to the other since they are obtained at considerably different initial assumptions. However, both relations contain the left-hand derivative of the function $x(t)$ at the point $t=t_{*}$. In the simplest case, when creep is neglected, this left-hand derivative is expressed by $\varepsilon^{\prime}\left(t_{*}-0\right)$. It is just this strain rate $\varepsilon^{\prime}$ that was registered in the experiment at the moment before the fracture (see Fig. 1 and Tables 1, 2; Tables 1,2 give the values of $t_{*}$ for organoplastic and glass plastic, respectively). It is obvious that the allowance for real velocity of specimen loading gives an increase in the critical fracture time $t_{*}$ as compared to the case when the loading applied instantly remains constant $/ 12 /$.

Table 1

$\begin{array}{lcccccccccr}\text { No. } & 1 & 2 & 3 & 4 & 5 & 6 & 7 & 8 & 9 & 10 \\ \varepsilon^{\prime} \mathrm{S}^{-1} & 105 & 165 & 210 & 100 & 70 & 205 & 250 & 160 & 170 & 45 \\ t_{*} \mu \mathrm{S} & 310 & 220 & 200 & 300 & 350 & 170 & 200 & 210 & 250 & 540\end{array}$

\begin{tabular}{lrrrrrrrrrr} 
No. & 1 & 2 & 3 & \multicolumn{1}{c}{4} & 5 & 6 & 7 & 8 & 9 & 10 \\
$\varepsilon^{-1}$ & 34 & 70 & 60 & 70 & 55 & 80 & 150 & 132 & 120 & 50 \\
$t_{*} \mu \mathrm{S}$ & 470 & 310 & 360 & 350 & 300 & 220 & 160 & 170 & 160 & 320
\end{tabular}

\section{REFERENCES}

1. Kokoshvili S.M. Methods of dynamic testing for rigid polymer materials. Riga, Zinatne, 1978 .

2. Chamis C.C., Smith G.T. AIAA Journal, 1984, v.22, No.1.

3. Daniel I.M., Labedz R.H., Liber T. Exp. Mechanics, 1981, v.11, No. 2 .

4. Ivanov A.G., Tsypkin V.I. Mechanics of composite materials, 1978 , No.3.

5. Fedorenko A.G., Tsypkin V.I. et al. Mechanics of composite materials, 1988, No.2.

6. Kachanov L.M. Foundations of fracture mechanics, Moscow, Nauka, 1974 .

7. Arutyunyan R.A. Strength problems, 1984, No.6.

8. Stepanov V.A., Peschanskaya N.N. Shpeizman V.V. Strength and relaxation in solids, Leningrad, Nauka, 1984.

9. Yevgraphov M.A. Asymptotic estimates and integral functions. Moscow, Izd. fiziko-matematicheskoi literatury, 1962.

10. Tamuzh V.P., Kuksenko V.S. Micromechanics of fracture of polymer materials. Riga, Zinatne, 1978.

11. Bertenev G.M. Strength and mechanism of polymer fracture, Moscow, Khimiya, 1984.

12. Zhurkov S.N. Vestnik AN SSSR, 1957, No.11. 